LIBRI

www.libridergi.org

Kitap Tanıtımı, Eleştiri ve Çeviri Dergisi

Journal of Book Notices, Reviews and Translations

Volume I (2015)

P. C. MILLER, Geç Antikçağda Düş Görme, Bir Kültürün Düş Gücüne

İlişkin Araştırmalar. İstanbul 2015. Kabalcı Yayınevi, 459 sayfa. Çev.:

Medet YOLAL. ISBN: 9786055093044

\section{Şenkal KiLECi}

Libri: Kitap Tanıtımı, Eleştiri ve Çeviri Dergisi'nde bulunan içeriklerin tümü kullanıcılara açık, serbestçe/ücretsiz 'açık erişimli' bir dergidir. Kullanıcılar, yayıncıdan ve yazar(lar)dan izin almaksızın, dergideki makaleleri tam metin olarak okuyabilir, indirebilir, dağıtabilir, makalelerin çıktısını alabilir ve kaynak göstererek makalelere bağlantı verebilir.

Libri, uluslararası hakemli elektronik (online) bir dergi olup değerlendirme süreci biten makaleler derginin web sitesinde (www.libridergi.org) yıl boyunca ilgili sayının içinde (Volume I: Ocak-Aralık 2015) yayımlanır. Aralık ayı sonunda ilgili yıla ait sayı tamamlanır.

Dergide yayımlanan eserlerin sorumluluğu yazarlarına aittir.

Künye P. C. MILLER, Geç Antikçağda Düş Görme, Bir Kültürün Düş Gücüne Illişkin Araştırmalar. İstanbul 2015. Kabalcı Yayınevi, 459 sayfa. Çev.: Medet YOLAL. ISBN: 9786055093044. Tanıtan: Şenkal KILECI, Libri I (2015) 57-58. DOI: 10.20480/lbr.2015115465

Geliş Tarihi: 03.10.2015

Kabul Tarihi: 06.10.2015

Online Yayın Tarihi: 29.12.2015

URL: http://dx.doi.org/10.20480/lbr.2018115465

Editörya Phaselis Project

www.phaselis.org 


\title{
P. COX MILLER, Geç Antikçağda Düş Görme, Bir Kültürün Düş Gücüne İlişkin Araştırmalar. İstanbul 2015. Kabalcı Yayınevi, 459 sayfa. Çev.: Medet YOLAL. ISBN: 9786055093044
}

\begin{abstract}
Şenkal KiLECi*
Dreams in Late Antiquity, Studies in the Imagination of a Culture adıyla 1994 yılında Princeton Üniversitesi Yayınları aracılığıyla basılan eser, 2015 yılında Geç Antikçağda Düş Görme, Bir Kültürün Düş Gücüne iliş̧kin Araştırmalar adıyla Türkçe'ye çevrilerek okurların bilgisine sunulmaktadır. Eser, İçindekiler (7-8), Teşekkür (9-12), Kısaltma Listesi (13-14), iki ana kısım ve Sonuç (423-428), eski ve çağdaş kaynakları ayrı iki başık altında toplayan bir Kaynakça (429-452) ile Dizin (453-459) başlıklarından oluşmaktadır. Düş Görmenin Imgeleri (17-213) adını taşıyan birinci kısım altında Giriş (17-33) ve dört ayrı bölüm; Düş Görenler (217-422) adını taşıyan ikinci kısım altında ise, Giriş (217-223) ve beş ayrı bölümde incelenmektedir.

Düş Görmenin Imgeleri (17-213) adını taşıyan birinci kısım oneiron (düş) ve eidōlon (imge) kavramlarını ele almaktadır. Düş Kişileri başlığını alan birinci bölümde (34-73), düş ve imge kavramları hem Hellen hem de Latin yazarların eserlerindeki rüya anlatımları doğrultusunda imlenerek, düşler köyü/ülkesi ve aynı zamanda 'düş insanları' olarak da çevrilen dēmos oneirōn terimi hem mimarî hem de insanî açıdan ele alınmaktadır. Sırasıyla Homeros, Ovidius, Vergilius ve Lucianus'un eserlerinde geçen düşler ülkesi tasvirlerinin benzerliklerine ve eserlerdeki tasvirî gelişimlerine, Euripides'in düş tanımlamasına değinilmektedir. İkinci bölümde (74-131) konu Düş Kuramları başlığı altında, düşlerin ruh ile ilgili bağlantısına psiko-biyolojik (79-93) ve dinbilimsel (93-94) kuramlarla yaklaşılmakta, praesensio (kötü bir şeyi sezmek) ve praesentio (öncesinde hissetmek) kavramları ile kehanet niteliği taşıyan düşler, Stoa felsefesi perspektifinde açıklanmaya çalışılmaktadır. Orta Dönem Platoncu'larının düşlere daimon'cu bakış açıları, Plutarkhos ve Apuleius örnekleriyle incelenmekte; rüya daveti için Papyri Graecae Magicae'dan seçilen büyü yazmalarından örnekler verilerek konu melek, ruh ve hayaletler ile dinsel psikoloji (118-132) üzerine yorumlamalarla genişletilmektedir. Bu hususta, kabul edilmiş bir düş kuramı oluşturan ilk geç antikçağ yazarı Kartacalı Tertullianus' un De Anima adlı eserine yer verilerek onun "insanların, tanrı bilgisini düşlerden öğrendiği" açıklaması üzerinde durulmaktadır. Düşlerin Yorumlanması (132-184) başlıklı üçüncü bölümde Greko-Romen düş yorumlamalarına çeşitli örneklerle açılımlar getirilmektedir. Bir düşün farklı yorumlar içerebileceğini hahamlara dair bir örnekle açıklamaya çalışan yazar, sırasıyla MS II. ve MS V. yüzyılda yaşamış olan Artemidoros ve Makrobios'un düşleri sınıflandırma ve yorumlama şekillerine değinmektedir. Artemidoros düşleri theōrēmatikoi oneiroi (görüldüğü gibi gerçekleşen; anlambilimsel düşler) ve allēgorikoi oneiroi
\end{abstract}

\footnotetext{
* M.A., Akdeniz Üniversitesi, Akdeniz Uygarlıkları Araştırma Enstitüsü, Akdeniz Eskiçağ Araştırmaları Anabilim Dalı, Antalya. senkalkileci@gmail.com
} 
(simgesel anlatımlı; imbilimsel düşler) şeklinde ikiye ayırırken Makrobios bilgesel, kehanet içeren ve beş türden (kişisel, yabanıl, toplumsal, kamusal, evrensel) oluşan anlaşılmaz düşler olarak üç ana sınıfa ayırmaktadır. Artemidoros'un Oneirokritikoi (Düş Yorumlamaları) ve Makrobios'un, Cicero'nun Devlet Üzerine başlıklı kitabındaki Somnium Scipionis (Scipio'nun Düşü) adlı bölüme yönelik kaleme aldığı Commentarii in Somnium Scipionis (Scipio'nun Düşü Üzerine Yorumlar) isimli çalışmasından örnekler ve yorumlar ile kutsal kitaptan (Gen. 28.10-18) Yakub’un düşüne yönelik, İskenderiyeli Philon ve Clemens'in değerlendirmelerine yer verilmektedir. Bu konu düşünür Gaston Bachelard'ın "figürleri farklı görünümleriyle anlıyoruz" sözüyle son bulur. Birinci kısmın son bölümü olan Düşler ve Tedavi (185-213) başlıklı dördüncü bölümde konu iki aşamada ele alınmaktadır; Asclepius Kültü (190-203) ve Sağaltıcı Düşler ve Büyü (203-213). illk konu kapsamında, Asklepios kült alanlarında yapılan çalışmalara, bu alanlarda nasıl davranılması gerektiğine değinilmekte ve görülen düşlerin kayıtlarına uzanan bir anlatı silsilesi takip edilmektedir. İkinci konuda ise, büyü kavramından yola çıkılarak düşleri ilgilendiren büyülü yazılar iki kategoride incelenmektedir: birinin düş görme isteği ve başka birine düş gönderme isteği. Bu hususta konu Papyri Graecae Magicae'dan alınan rüyasal büyü şablonlarına, rüyaya davet ve sağaltıcı rüya büyülerine örnekler verilerek genişletilmektedir.

Eserin ikinci kısmı olan Düş Görenler (217-422) bölümünde yazar, detaylı incelemeler yapmak üzere, Hermas ve Çoban (224-251), Perpetua ve Düş Günlüğü (252-311), Aelius Aristides ve Kutsal Öyküler (312-346), Jerome ve Düşleri (347-392) ve Iki Gregory ve Sofuca Düş Görme (393428) başlıkları altında seçtiği düşsel denemeleri incelemektedir. Bu düşler öncelikle düş kişisi açısından değerlendirilip yorumlanmaktadır. Ele alınan kişilerin yaşadıkları dönem temel alınmakta ve düşler Hıristiyanlık, Martyrizm, din ve kadın gibi konuları barındırmaktadır. Bu bölümde seçilen düşler; düş kişisinin duası, istiareye yatması, bilincine karşı durması sonucu oluşmuştur.

Sonuç (423-428) bölümünde yazar, California Üniversitesi'nden Hélène Cixous'nun çağcıl dünyada düşe ait kaynakların kaybedilmiş olmasına ilişkin üzüntüsünü alıntıladığı sözlerle aktarmaktadır. Antikçağda düşlerin gündelik yaşam ve düşüncelerle bağlantılı olduğunu; ayrıca geç antikçağda, düş görmenin yaşamı farklı açılardan kavramaya ışık tuttuğu düşüncesinin benimsendiğini vurgulayarak eserine son vermektedir. 